\title{
вмј Global Health Violence against children in South Africa: the cost of inaction to society and the economy
}

\author{
Celia Hsiao, ${ }^{1,2}$ Deborah Fry, ${ }^{3}$ Catherine L Ward, ${ }^{4,5}$ Gary Ganz, ${ }^{4}$ Tabitha Casey, ${ }^{3}$ \\ Xiaodong Zheng, ${ }^{6}$ Xiangming Fang ${ }^{6,7}$
}

To cite: Hsiao C, Fry D, Ward CL, et al. Violence against children in South Africa: the cost of inaction to society and the economy. BMJ Glob Health 2018:3:e000573. doi:10.1136/ bmjgh-2017-000573

Handling editor Seye Abimbola

Received 18 September 2017 Revised 16 November 2017 Accepted 7 December 2017

\section{(a) CrossMark}

${ }^{1}$ Save the Children South Africa, Pretoria, South Africa

${ }^{2}$ Faculty of Health Sciences, MRC/Wits Developmental Pathways for Health Research Unit, University of the Witwatersrand, Johannesburg, South Africa

${ }^{3}$ Moray House School of Education, University of Edinburgh, Edinburgh, UK ${ }^{4}$ Department of Psychology, University of Cape Town, Cape Town, South Africa

${ }^{5}$ Safety and Violence Initiative, University of Cape Town, Cape Town, South Africa

${ }^{6}$ College of Economics and Management, China Agricultural University, Beijing, China ${ }^{7}$ School of Public Health, Georgia State University, Atlanta Georgia

Correspondence to

Dr Celia Hsiao;

CHsiao@savethechildren.org.za

\section{ABSTRACT}

Despite the extent and magnitude of violence against children in South Africa, political and financial investments to prevent violence against children remain low. A recent costing study investigating the social burden and economic impact of violence against children in South Africa found notable reductions to mental and physical health outcomes in the population if children were prevented from experiencing violence, neglect and witnessing family violence. The results showed, among others, that drug abuse in the entire population could be reduced by up to $14 \%$ if sexual violence against children could be prevented, self-harm could be reduced by $23 \%$ in the population if children did not experience physical violence, anxiety could be reduced by $10 \%$ if children were not emotionally abused, alcohol abuse could be reduced by $14 \%$ in women if they did not experience neglect as children, and lastly, interpersonal violence in the population could be reduced by $16 \%$ if children did not witness family violence. The study further estimated that the cost of inaction in 2015 amounted to nearly 5\% of the country's gross domestic product. These findings show that preventing children from experiencing and witnessing violence can help to strengthen the health of a nation by ensuring children reach their full potential and drive the country's economy and growth. The paper further discusses ways in which preventing and ending violence against children may be prioritised in South Africa through, for instance, intersectoral collaboration and improving routine monitoring data, such as through the sustainable development goals.

\section{INTRODUCTION}

Globally, South African children experience disproportionally high levels of violence, and there is now mounting evidence on the magnitude of violence against children (VAC). ${ }^{1}$ South Africa's estimated child homicide rate of 5.5 homicides per 100000 children is more than twice the global average, and nearly half of all child homicides in South Africa were related to child abuse and neglect. ${ }^{2}$ In $2013 / 2014,29 \%$ of sexual offences reported to the police involved children under the age of 18years: approximately 51 cases of child sexual victimisation per day. ${ }^{3}$ Issues of

\section{Key questions}

What is already known about this topic?

- Violence against children can have adverse consequences on health outcomes, health risk behaviours and is associated with subsequent perpetration of violence.

What are the new findings?

- For the first time, evidence from South Africa shows that experiences of violence, neglect and witnessing family violence during childhood can have measurable effects on the country's social and health outcomes.

- Furthermore, violence against children has massive implications for South Africa's economic health.

- Together, these findings contribute to building an investment case and to motivate political will to prevent and end violence against children in South Africa.

\section{Recommendations for policy}

- This analysis helps policy makers to understand the burden of violence against children within a social and economic context, as well as places it as a public health priority by comparing it with other leading public health concerns affecting South Africa.

- There are key opportunities in South Africa to improve the collection of routine monitoring data and significantly contribute to the global evidence base through the sustainable development goals.

under-reporting, however, are severe, and actual rates of VAC are estimated to be much higher. $^{4-6}$

A recent study provided nationally representative data on the prevalence of VAC. ${ }^{\text {? }}$ The study found one in five children $(19.8 \%)$ experienced sexual abuse, compared with $18 \%$ in the global average for girls and $8 \%$ for boys, one in three $(34.4 \%)$ experienced physical abuse, a notable increase from the global average of $23 \%$, one in six $(16.1 \%)$ reported experiencing emotional abuse compared with the global average of $36 \%$, one in eight 
$(12.2 \%)$ reported being neglected in comparison with the global average of $16 \%^{8}$ and one in six $(16.9 \%)$ reported witnessing violence.

Another study critically analysed the risk and protective factors associated with VAC in South Africa at the individual, relationship and community society level. ${ }^{9}$ The authors found children at highest risk of violence when living in households where neither parent is present, where financial resources were scarce and where they were exposed to drugs, alcohol, crime and conflict. Children were also more at risk if they had greater exposure to community members involved in drugs, alcohol and crime.

Despite recent efforts to generate substantive evidence on the determinants and severity of VAC in South Africa, evidence relatively rare from low-income and middle-income countries (LMICs), there remains a paucity of both political and financial investment to prevent children from experiencing violence, as is the case in many LMICs. In this paper, we present new findings estimating the social burden and economic impact of VAC in South Africa, discuss recent efforts made to prioritise violence prevention, identify key stumbling blocks in advancing the national agenda and discuss potential avenues to pursue in order to appeal to policy makers to identify $\mathrm{VAC}$ as a national priority.

\section{The social burden of VAC: impact on health and violence perpetration}

Globally, substantial neuroscientific evidence has amassed on the adverse consequences of experiencing violence during childhood on later health outcomes, health risk behaviours and subsequent perpetration of violence. ${ }^{10-15}$ This body of work shows that through repeated experiences or witnessing of violence, the neuroendochrine, autonomic, immunological and neuropsychological systems become excessively activated. This results in children's bodies remaining in a constant state of high stress through increased heart rate, hypervigilance and elevated secretions of cortisol. ${ }^{10}$ Such chronic stress and fear can have damaging effects on a myriad of outcomes, including mental health and coping mechanisms, which can range from depression to alcohol and drug abuse, ${ }^{1112}$ health consequences such as heart disease and suicide, ${ }^{1314}$ as well as impaired learning, socialisation and productivity. ${ }^{15}$

In terms of behavioural adaptations and violence perpetration, such reactions to stress may become normalised

Table 1 Population attributable fractions for health and risk behaviour outcomes associated with violence against children

\begin{tabular}{|c|c|c|c|c|c|c|c|c|c|}
\hline & SMI & Depression & Anxiety & $\begin{array}{l}\text { Alcohol } \\
\text { abuse }\end{array}$ & $\begin{array}{l}\text { Drug } \\
\text { abuse }\end{array}$ & STDs & HIV & $\begin{array}{l}\text { Interpersonal } \\
\text { violence }\end{array}$ & $\begin{array}{l}\text { Self- } \\
\text { harm }\end{array}$ \\
\hline \multicolumn{10}{|c|}{ Sexual violence } \\
\hline Total & - & - & 0.06 & - & 0.14 & 0.03 & - & - & 0.12 \\
\hline Male & - & - & - & 0.07 & - & - & - & 0.03 & - \\
\hline Female & - & 0.06 & - & 0.1 & - & 0.08 & 0.05 & 0.07 & - \\
\hline \multicolumn{10}{|c|}{ Physical violence } \\
\hline Total & 0.1 & - & 0.13 & 0.13 & 0.11 & - & - & 0.04 & 0.23 \\
\hline Male & - & - & - & - & - & - & - & 0.08 & - \\
\hline Female & - & - & - & - & - & - & 0.22 & 0.12 & - \\
\hline \multicolumn{10}{|c|}{ Emotional violence } \\
\hline Total & 0.05 & - & 0.1 & 0.04 & 0.05 & - & - & 0.03 & 0.15 \\
\hline Male & - & - & - & 0.03 & - & - & - & - & - \\
\hline Female & - & - & - & - & - & - & 0.12 & - & - \\
\hline \multicolumn{10}{|l|}{ Neglect } \\
\hline Total & - & - & 0.08 & - & - & - & - & - & - \\
\hline Male & - & 0.16 & - & - & 0.04 & - & - & - & - \\
\hline Female & - & 0.09 & - & 0.14 & - & 0.06 & - & - & - \\
\hline \multicolumn{10}{|c|}{ Witnessing family violence } \\
\hline Total & - & - & 0.13 & - & - & - & - & - & - \\
\hline Male & - & - & - & - & - & - & - & 0.16 & - \\
\hline Female & - & - & - & - & - & - & - & 0.16 & - \\
\hline
\end{tabular}

Adapted from: Fang et al. ${ }^{17}$

Notes: '-' indicates not applicable. PAF calculated using prevalence of type of violence against children and relative rate of outcome of interest. PAFs were calculated for outcomes on which data were available.

PAF, population attributable fractions; SMI, serious mental illness; STDs, sexual transmitted diseases. 


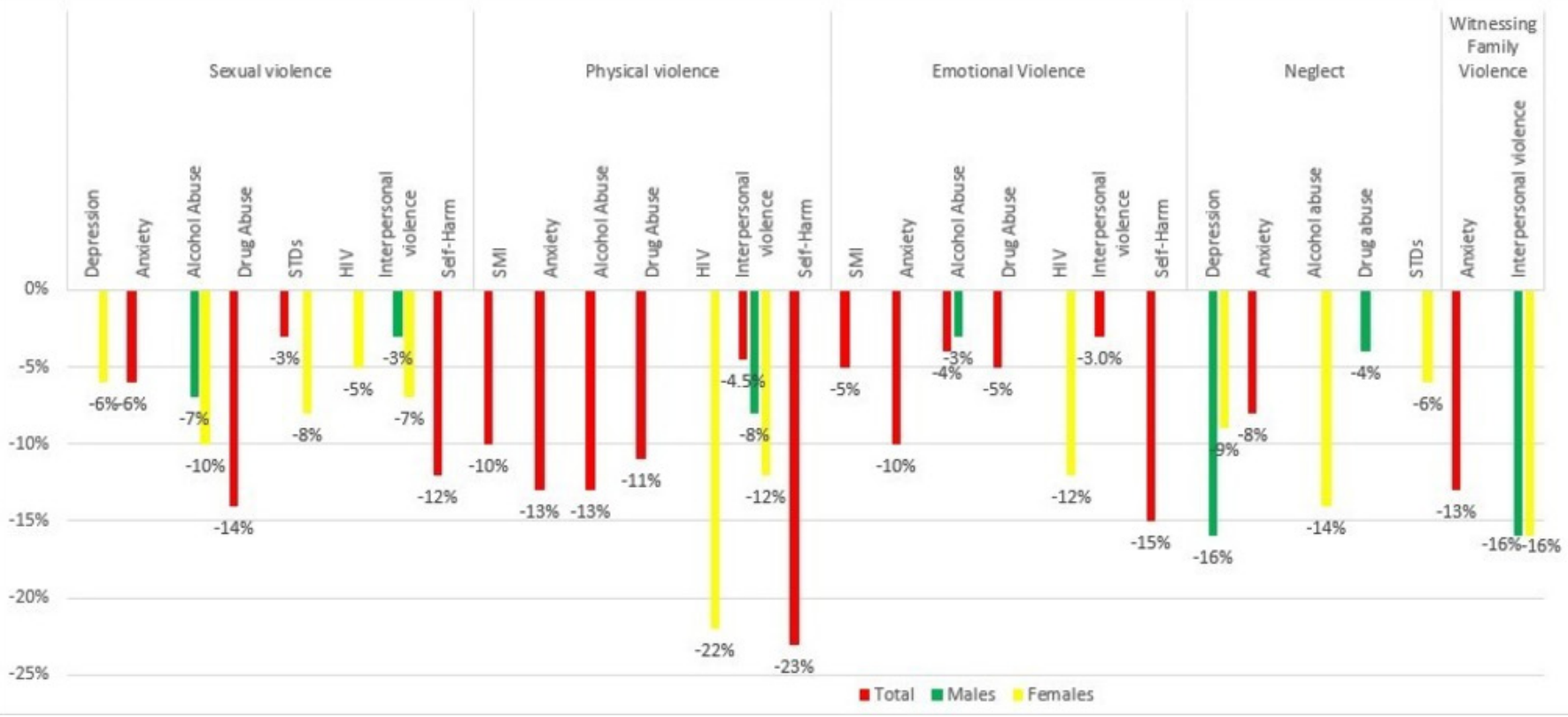

Figure 1 Reductions in negative health and risk behaviour outcomes if different forms of violence against children could be prevented. Note: (1) self-harm includes suicide ideations and suicide attempts. (2) Gender breakdown is provided where data are available. SMI, serious mental illness; STDs, sexual transmitted diseases.

causing individuals to respond to others aggressively or perceive aggression in others even when no threat is present. This is because the overactivated stress response system has been programmed to adapt to such negative situations, and thus the child remains in a state that expects the situation to be adverse. These children thus have a lowered threshold for aggression. ${ }^{10}$

Several studies have demonstrated the burden of early experiences of violence on health and other outcomes. Fry and Blight $^{16}$ recently found that different types of violence experienced during childhood contributes significantly to proportions of mental disorders in the Asia and Pacific region. The study also found that preventing VAC could help to reduce a wide range of risk behaviours (eg, teenage pregnancy in girls and use of illicit drugs in adolescence and adulthood).

In order to investigate the social and health impact of experiences of childhood violence in South Africa, we undertook a costing study to investigate the consequences of VAC on the South African society and economy. First, we calculated population attributable fractions (PAF) for data that was available to define the relationship between various types of violence experienced during childhood (sexual, physical, emotional, neglect and witnessing family violence) and negative outcomes (severe mental illness, depression, anxiety, alcohol and drug abuse, sexual transmitted diseases (STDs), HIV, interpersonal violence and self-harm). Two pieces of data were required to calculate PAFs: (1) relative risk (RR) of a disease or outcome (eg, depression) given exposure to a risk factor (VAC) or an OR that can be converted into an approximate estimate of the RR and (2) a measure of prevalence. The prevalence data came from the Optimus Study South Africa, the first nationally representative study of VAC in South Africa. ${ }^{7}$ A systematic review and meta-analysis based on literature published between 2000 and 2015 was conducted to establish associations (RRs or ORs) between experiences of violence during childhood and later negative outcomes. ${ }^{17}$ RRs needed for PAFs were based on 24 studies identified by the systematic review and the analysis findings from the secondary analysis of the Cape Area Panel Study dataset. ${ }^{17}$ Of the 24 studies, most were cross-sectional studies $(\mathrm{n}=18)$ and were conducted in multiple provinces. A total of 11 studies were conducted in various provinces, while 5 studies were from the nationally representative South African Stress and Health study, a population-based study gathering mental health and behavioural information, and exposure to various traumas, including violence during childhood. $^{218}$ Table 1 provides PAFs for outcomes associated with various forms of VAC.

Using these PAFs, figure 1 presents reductions in health and risk behaviours if VAC were entirely eliminated. Specifically, if sexual VAC were prevented:

- Depression in adult women and anxiety in South Africa could be reduced by $6 \%$.

- Alcohol abuse could be reduced by $7 \%$ in men and $10 \%$ in women.

- Drug abuse in the entire population could be reduced by $14 \%$.

- STDs in the entire population could be reduced by $3 \%$ and in women by $8 \%$.

- HIV in women could be reduced by $5 \%$.

- Interpersonal violence could be reduced by $3 \%$ in men and $7 \%$ in women.

- Self-harm could be reduced by $12 \%$ in the entire population. 
The following reductions could be made if physical VAC were prevented:

- serious mental illness by $10 \%$ in the entire population

- anxiety and alcohol abuse by $13 \%$ in the entire population

- drug abuse by $11 \%$ in the entire population

- HIV by $22 \%$ in women

- interpersonal violence by $4 \%$ in the entire population, $8 \%$ in men and $12 \%$ in women

- self-harm by $23 \%$ in the entire population.

In terms of emotional violence, the following reductions could be made if it were prevented:

- serious mental illness by $5 \%$ in the entire population

- anxiety by $10 \%$ in the entire population

- alcohol abuse by $4 \%$ in the entire population and $3 \%$ in men

- drug abuse by $5 \%$ in the entire population

- interpersonal violence by $3 \%$ in the entire population

- self-harm by $15 \%$ in the entire population.

The following reductions could be made if children

did not experience neglect:

- depression by $16 \%$ in men and $9 \%$ in women

- anxiety by $8 \%$ in the entire population

- alcohol abuse by $14 \%$ in women

- drug abuse by $4 \%$ in men

- STDs by $6 \%$ in women.

Lastly, the following reductions could be made if children did not witness family violence:

- anxiety by $13 \%$ in the entire population

- interpersonal violence by $16 \%$ in both men and women.

\section{The economic impact of VAC: the costs of inaction}

It is to no surprise, given the negative effects of experiences of violence on children's health which, in many cases endure into adulthood, that VAC has a significant national economic impact. VAC significantly increases a country's burden of mortality as well as physical and emotional disability. In 2000, violence and unintentional injuries combined were the second leading cause of death and numbers of years lost due to disability in South Africa after HIV/AIDS. ${ }^{19}$

The disability-adjusted life year (DALY) is a measure of overall disease burden and measures the total number of healthy living years lost due to disability, poor health or early death caused by a disease. Measures of DALYs are useful to understand the impact of a disease on economic health as one healthy living year lost due to disability, ill health or death thwarts the capacity to contribute to the economy. VAC, if not prevented, can deplete children's cognitive capital, referring to a set of intellectual skills such as communication, problem solving and decision making, which determines their ability to work and contribute to the economy. ${ }^{20}$ The second goal of the costing study was thus to examine the impact of the negative outcomes, resulting from experiences of violence during childhood, on South Africa's economy.
Based on the findings from the literature review and data analyses, we estimated the DALYs lost due to VAC-attributable physical and mental health outcomes and health-risk behaviours and then estimated the monetary value of those DALYs in 2015 South African rand. For each main type of non-fatal VAC that we considered, a PAF for an outcome of interest was multiplied by the estimate of the number of the DALYs expected to be lost because of that outcome. PAFs of our selected health and behavioural outcomes (alcohol abuse, drug abuse, STDs, HIV, interpersonal violence, self-harm, serious mental illness, depression and anxiety) were matched to definitions of 'alcohol use', 'drug use', 'STDs excluding HIV', 'HIV/AIDS', 'interpersonal violence', 'self-harm', 'mental disorders', 'depressive disorders' and 'anxiety disorders' from the Global Burden of Disease Study $2015 .^{21}$ The DALYs lost from fatal cases of VAC were calculated as the number of child deaths multiplied by a loss function specifying the years lost for deaths as a function of the age at which death occurs. ${ }^{17}$

The total cost calculations included: (1) monetary value of DALYs lost from both fatal cases of VAC as well as the negative health outcomes and health risk behaviours due to non-fatal forms of VAC; (2) reductions in earnings due to physical and emotional violence experienced during childhood; and (3) child welfare costs. DALY losses were converted into a monetary value by assuming that 1 year lived with disability or 1 year of life lost due to violence equates to a year lost from the productive capacity of a country's economy which, on average, is equal to the per capita gross domestic product (GDP). ${ }^{22}{ }^{23}$ See Fang et al ${ }^{17}$ for details on costing model.

Results showed that for non-fatal forms of VAC, physical violence cost US $\$ 6.7$ billion (in 2015 US dollars), sexual violence cost US $\$ 2.1$ billion, emotional violence cost US $\$ 3.6$ billion and neglect cost US $\$ 537$ million. Fatal forms of violence cost US $\$ 486$ million, while reductions in earnings due to physical violence and emotional violence cost US $\$ 2.0$ billion and US $\$ 750$ million, respectively. Child welfare costs, which refer to expenditure on child care and protection, amounted to US $\$ 124$ million, although this was an underestimate as several costs could not be determined from the relevant government reports. Taken together, the study estimated that VAC cost the South African economy US $\$ 15.81$ billion or nearly $5 \%$ of the country's GDP, ${ }^{\mathrm{i}}{ }^{\mathrm{ii}}$ whereas a similar costing study conducted in the Asia and Pacific region found the total cost to be nearly $2 \%$ of the region's GDP. ${ }^{24}$

\footnotetext{
${ }^{i}$ Note that at the time of the study, the analysis was based on 2012 Global Burden of Disease Study (GBD 2014). The figures reported in this paper are based on the recently released 2015 GBD study and hence differ slightly from those in the original report.

${ }^{\text {ii }}$ We would like to thank an anonymous reviewer for pointing out that the estimation model is based on many assumptions that could increase or reduce the estimated cost of 5\% of SA's GDP, such as the assumption that much of the population affected would not earn an average per capita GDP, or that there is underreporting. We recognize this as an important limitation to the model.
} 


\section{Hurdles to progress and way forward}

These findings demonstrate that investing in violence prevention can yield significant economic returns in reducing adverse health outcomes and loss in productivity. Notable efforts have been made in South Africa to address the issue of VAC. These include, for instance: establishment of a cabinet level Inter-Ministerial Committee (IMC) in 2010 to address violence against women and children; research yielding compelling evidence on the magnitude, determinants, consequences and now cost of VAC; a national integrated programme of action (PoA) addressing violence against women and children (2013-2018) ${ }^{25}$; and a series of effectiveness and evaluation studies of interventions shown to reduce children's emotional, conduct and peer problems, ${ }^{26}$ improve children's cognitive development, ${ }^{27}$ improve motherchild relationship $^{28}$ and reduce violence. ${ }^{29}$

However, VAC remains widespread, and the success of violence prevention relies on government identifying such an investment as a strategic national priority, ${ }^{30} \mathrm{a}$ common dilemma globally. ${ }^{20} \mathrm{~A}$ recent diagnostic review commissioned by the IMC examined the state's response to violence against women and children. The review proposed a series of recommendations including a relaunch of the PoA over the next 5 years to include a fully costed plan; a better policy and programme direction for the sector; improved monitoring and evaluation data to better track and assess the performance of state provided services and interventions; and a need to establish an oversight body to the sector in order to hold lead state departments accountable on progress. ${ }^{31}$ These recommendations, while critical to move the sector forward, will only be realised and appropriately resourced if VAC is regarded as a national priority.

Currently, VAC is not viewed as a significant human rights or public health issue in South Africa. Based on findings from the costing study, the total number of healthy living years lost (DALYs) due to violence against South African children was 2.3 million (non-fatal) in 2015, an amount that is more than diabetes (1.1 million DALYs lost) and cardiovascular diseases (2.1 million DALYs lost), ${ }^{21}$ which are leading non-communicable diseases affecting South Africans. When compared with what some may see as the leading public health concern, HIV/AIDS, the study found that VAC contributed as many as $32 \%$ of the DALYs lost to HIV/AIDs in 2015. Such evidence is critical to policy makers in understanding the health and economic impact of VAC and in informing their decisions on budgetary and resource allocations. Currently, prevention and early intervention services, under which state violence prevention programmes are funded, account for less than $1 \%$ of the combined national and provincial Department of Social Development budget, furthermore, all provinces with the exception of one plan decreases in the share going to these services over the period of 2016/2017 to 2018/2019. ${ }^{32}$

Despite providing one of the most progressive and inclusive constitutions in the world with laws that are human rights focused and include the right to live without violence, and also having signed the Convention on the Rights of the Child, South Africa's translation of policies protecting children from violence into practice has been poor. ${ }^{25}$ To address this 'implementation gap', a concerted effort between government, researchers and development partners is necessary to build a communication bridge in order to facilitate the seamless flow of information and evidence. ${ }^{33}$ For instance, while researchers test the effectiveness of violence prevention programmes to show whether a programme works, such as Stepping Stones, ${ }^{34}$ and the suite of interventions through Parenting for Lifelong Health, ${ }^{35}$ a corresponding effort is needed to assess which programmes are most cost-effective as this is the evidence required by policy makers in decisions around budget allocations. In this sense, government needs to make explicit the type of evidence needed to inform their decisions, while researchers and development agencies need to align their measurements and targets to factor in calculations on return on investment. Similarly, as civil society and community-based organisations deliver violence prevention programmes in communities, they need to systematically document their real-world implementation challenges, ${ }^{36}$ which often remain unknown outside of the development sphere and share them with researchers and government so that they can be considered in the design and measurement of interventions as well as adequately resourced.

A key step is that researchers who generate innovation and evidence must be able to make their work accessible to those without content matter expertise by building capacity on interpreting their results and communicating them in a way that is pertinent and usable to government and development agencies. One example of how this may work comes from research conducted in Cameroon and South Africa: Naude et $a l^{37}$ proposed a Building Demand for evidence in Decision-making through Interaction and Enhancing Skills approach that seeks to increase the interface between researchers and policy makers to build capacity in evidence informed decision making. The authors propose a model to increase dialogue between policy makers and researchers from thinking through policy and research questions together, including issues around feasibility and implementation, through to researchers understanding the policy process and the priorities of policy makers and policy makers working with researchers to use research evidence in decision making.

There are also basic steps that government can take immediately. With the exception of the recent nationally representative prevalence study on VAC, South Africa lacks a reliable national and subnational database on VAC. Without national surveillance data to routinely identify the nature, magnitude and geographic distribution of VAC, it is difficult to inform and develop targeted and effective programmes. To further strengthen the database, there is a need to improve national registers on child offenders to prevent them from reoffending. ${ }^{31}$ In South Africa, the Child Protection Register and the 
National Register of Sexual Offenders keep records of adults not suitable to work with children and hence preventing them from further child abuse. However, the two registers have been found to be ineffective due to a high demand on human capacity, loss of historical files, poor input and use of information and a high maintenance cost for both registers. ${ }^{31}$ There is a need to synchronise the two systems and streamline its effectiveness and utility.

Donors and international development agencies also have their role to play. For instance, the United Nations Development Programme has selected South Africa as a pilot country on the domestication of Goal 16 of the Sustainable Development Goals, which includes targets 16.1 'Significantly reduce all forms of violence and related death rates everywhere' and 16.2 'End abuse, exploitation, trafficking and all forms of violence and torture against children'. A key objective is to develop reliable, objective and independent monitoring systems of the indicators. This consultative process, led by Statistics South Africa, includes input from government, civil society and other institutions in developing a domestic indicator framework for South Africa. This process provides another critical opportunity to improve South African data on VAC and to generate routine monitoring data that can be used to motivate VAC as a national priority.

\section{CONCLUSION}

It is crucial that the deleterious societal and economic implications of VAC are understood by policy makers, and the general public, especially in LMICs, where resources are scarce, violence is sometimes pervasive, and the impact most damaging. This paper provides evidence to build an investment case for violence prevention in South Africa. The study showed that experiences of violence during childhood have measureable and far-reaching effects that can significantly debilitate the health of a nation and undermine its economy. Individuals who experience various forms of violence during childhood, whether it be sexual, physical, emotional, neglect or witnessing family violence, are at greater risk of later negative health, behavioural and interpersonal outcomes. Reducing and preventing children from experiencing violence allow them to reach their full human potential and at the same time reduces social and health burdens to our society including severe mental health illness, depression, anxiety, alcohol and drug abuse, interpersonal violence and self-harm. While a strong legislative framework exists to protect children from violence, its translation into practice has been slow. There is an urgent need to address the implementation gap by investigating the barriers and facilitators to implementation and for intersectoral collaboration to address gaps in information exchange and use of evidence generated through research to inform policy decisions.
Contributors $\mathrm{CH}$ wrote the manuscript. All coauthors provided significant input in the revision and final approval of the manuscript and meet the ICMJE authorship conditions.

Funding This work reported in this paper was funded from a grant from Save the Children Sweden Grant Number 75220290

Disclaimer The funder has had no role in the study design, analysis and interpretation of the data, in the writing of this manuscript, and in the decision to submit the manuscript for publication.

Competing interests Save the Children Sweden provided funding to conduct the costing analysis; however, the funder was not involved in the design and analysis of the study, nor in the conceptualisation or writing of this analysis paper.

Provenance and peer review Not commissioned; externally peer reviewed.

Data sharing statement № additional data are available.

Open Access This is an Open Access article distributed in accordance with the Creative Commons Attribution Non Commercial (CC BY-NC 4.0) license, which permits others to distribute, remix, adapt, build upon this work non-commercially, and license their derivative works on different terms, provided the original work is properly cited and the use is non-commercial. See: http://creativecommons.org/ licenses/by-nc/4.0/

(c) Article author(s) (or their employer(s) unless otherwise stated in the text of the article) 2018. All rights reserved. No commercial use is permitted unless otherwise expressly granted.

\section{REFERENCES}

1. Meinck F, Cluver LD, Boyes ME, et al. Physical, emotional and sexual adolescent abuse victimization in South Africa: Prevalence, incidence, perpetrators and locations. J Epidemiol Community Health 2016:1-7.

2. Mathews S, Abrahams N, Jewkes R, et al. The epidemiology of child homicides in South Africa. Bull World Health Organ 2013;91:562-8.

3. South African Police Services. Crime statistics: april 2013-March 2014. Pretoria: SAPS, 2014.

4. South African Police Services. SAPS strategic management annual report 2012/2013. Pretoria: SAPS, 2013.

5. Jamieson L, Sambu W, Mathews S. Out of harm's way? Tracking child abuse through the child protection system in five selected sites in South Africa. Cape Town: Children's Institute, University of Cape Town, 2017.

6. Meinck F, Cluver L, Loening-Voysey H, et al. Disclosure of physical, emotional and sexual child abuse, help-seeking and access to abuse response services in two South African Provinces. Psychol Health Med 2017;22:94-106.

7. Artz L, Burton P, Ward CL, et al; Optimus Study South Africa: Technical report. Sexual victimization of children in South Africa: Final report of the Optimus Foundation Study. Zurich, South Africa: UBS Optimus Foundation, 2016.

8. World Health Oraganization. Studies of child maltreatment prevalence. 2014. http://apps.who.int/violence-info/childmaltreatment

9. Mathews S, Govender R, Lamb G, et al; Towards a more comprehensive understanding of the direct and indirect determinants of violence against women and children in South Africa with a view to enhancing violence prevention. Safety and Violence Initiative: University of Cape Town, 2016.

10. Shonkoff JP, Richter L, van der Gaag J, et al. An integrated scientific framework for child survival and early childhood development. Pediatrics 2012;129:e460-72.

11. Horwitz AV, Widom CS, McLaughlin J, et al. The impact of childhood abuse and neglect on adult mental health: a prospective study. $J$ Health Soc Behav 2001;42:184-201.

12. Schilling EA, Aseltine RH, Gore S. Adverse childhood experiences and mental health in young adults: a longitudinal survey. BMC Public Health 2007;7:30.

13. Barker DJ. Fetal programming of coronary heart disease. Trends Endocrinol Metab 2002;13:364-8.

14. Dong M, Giles WH, Felitti VJ, et al. Insights into causal pathways for ischemic heart disease: adverse childhood experiences study. Circulation 2004;110:1761-6.

15. Lanius V, Vermetten E, Pain C. The impact of early life trauma on health and disease: the hidden epidemic. Cambridge: Cambridge University Press, 2010. 
16. Fry D, Blight S. How prevention of violence in childhood builds healthier economies and smarter children in the Asia and Pacific region. BMJ Glob Health 2016;1(Suppl 2):i3-i11.

17. Fang X, Fry DA, Ganz G, et al; The economic burden of violence against children in South Africa. Report to save the Children South Africa. Cape Town: China Agricultural University, and Universities of Cape Town and Edinburgh, 2016.

18. Williams DR, Herman A, Kessler RC, et al. The South Africa stress and health study: rationale and design. Metab Brain Dis 2004;19:135-47.

19. Norman R, Bradshaw D, Schneider M, et al; Revised burden of disease estimates for the comparative risk factor assessment. Cape Town: South African Medical Research Council, 2006.

20. Fry D. UNICEF. Preventing violence against children and how this contributes to building stronger economies. Kuala Lumpur: Thematic Research Paper for the 3rd High-Level Meeting on Cooperation for Child Rights in the Asia-Pacific Region, 7-9 November, 2016.

21. Global Health Data Exchange. GBD Results Tool. 2016. http://ghdx. healthdata.org/gbd-results-tool

22. Brown DW. Economic value of disability-adjusted life years lost to violence: estimates for WHO Member States. Rev Panam Salud Publica 2008;24:203-9.

23. World Health Organization (WHO). Macroeconomics and health. Investing in health for economic development. Geneva: WHO, 2001

24. Fang X, Fry DA, Brown DS, et al. The burden of child maltreatment in the East Asia and Pacific region. Child Abuse Negl 2015;42:146-62.

25. Department of Social Development (DSD). South African integrated programme of action addressing violence against women and children (2013-2018). Pretoria: South African National Department of Social Development, 2014.

26. Mathews S, Berry L, Marco J. An outcome assessment of a residential care programme for sexualy-abused children in South Africa. Cape Town: Children's Institute, University of Cape Town, 2016.
27. Vally Z, Murray L, Tomlinson M, et al. The impact of dialogic booksharing training on infant language and attention: a randomized controlled trial in a deprived South African community. J Child Psychol Psychiatry 2015:56:865-73.

28. Cooper PJ, Tomlinson M, Swartz L, et al. Improving quality of mother-infant relationship and infant attachment in socioeconomically deprived community in South Africa: randomised controlled trial. BMJ 2009;338:b974.

29. Cluver L, Lachman JM, Ward C, et al. Developing a parenting programme to prevent child abuse in South Africa: A pre-post pilot study. Research on Social Work Practice 2016. https://ora.ox.ac.uk/ objects/uuid:81292720-286c-4c72-b68d-db738933ed25

30. Seedat M, Van Niekerk A, Jewkes R, et al. Violence and injuries in South Africa: prioritising an agenda for prevention. Lancet 2009;374:1011-22.

31. KPMG. Report on the diagnostic review of the state response to violence against women and children: Department of Planning, Monitoring and Evaluation, Department of Social Development, 2016.

32. International Budget Partnership. Children and South Africa's social development budget. Pretoria: UNICEF, 2016.

33. Mikton C, Power M, Raleva M, et al. The assessment of the readiness of five countries to implement child maltreatment prevention programs on a large scale. Child Abuse Negl 2013;37:1237-51.

34. Jewkes R, Wood K, Duvvury N. "I woke up after I joined Stepping Stones": meanings of an HIV behavioural intervention in rural South African young people's lives. Health Educ Res 2010;25:1074-84.

35. World Health Organization. Parenting for Lifelong Health (PLH). http://www.who.int/violence_injury_prevention/violence/child/plh/en/

36. Wessels I, Lester S, Ward C. Engagement in parenting programmes. Institute for Security Studies Policy Brief 2016;82.

37. Naude CE, Zani B, Ongolo-Zogo P, et al. Research evidence and policy: qualitative study in selected provinces in South Africa and Cameroon. Implement Sci 2015;10:126. 